\title{
PERANCANGAN PETA POP-UP KISAH EKSODUS
}

\author{
Vanessa Yusuf, Mendy Hosana Malkisedek \\ Universitas Kristen Petra
}

\begin{abstract}
Abstrak. Kisah Eksodus merupakan peristiwa yang menceritakan keluarnya Bangsa Israel dari Mesir menuju Kanaan. Pada kegiatan belajar mengajar di sekolah minggu, cerita Eksodus menjadi salah satu kisah Alkitab yang sering dibahas, namun kisah ini melibatkan banyak tempat dan alur perjalanan yang berputar. Penjelasan tentang tempat dan alur perjalanan ini sangat penting untuk dapat memahami makna kisah Eksodus secara menyeluruh. Sehingga pada penelitian ini dirancang sebuah peta kisah Eksodus dengan pendekatan teknik pop-up / paper engineering yang sesuai untuk anak-anak. Metode kualitatif digunakan dalam penelitian ini, serta pengumpulan data melalui wawancara kepada guru sekolah minggu, hamba Tuhan, guru geografi, kemudian observasi dalam kelas sekolah minggu, tinjauan karya sejenis, serta kajian pustaka terkait kisah Eksodus, peta, dan paper engineering. Perancangan ini menghasilkan karya dalam bentuk peta pop-up yang berukuran A3 saat tertutup dan A2 saat terbuka, serta 10 pop-up / movables yang menjelaskan peristiwa-peristiwa dalam kisah Eksodus.
\end{abstract}

Kata Kunci: eksodus, peta pop-up, paper engineering, sekolah minggu, kisah Alkitab

\begin{abstract}
The story of the Exodus is an event that tells the departure of the Israelites from Egypt to Canaan. In the teaching and learning activities in Sunday school, the story of the Exodus becomes one of the Bible stories that is often discussed, but this story involves many places and journeys which are whirligig. Explanation of the place and plot of the trip is very important to be able to understand the meaning of the story of the Exodus as a whole. So that in this study a map of the story of the exodus was designed with the pop-up / paper engineering approach appropriate for children. Qualitative methods were used in this study, as well as data collection through interviews with Sunday school teachers, servants of God, geography teachers, then observations in Sunday school classes, review of similar works, and literature studies related to the story of the Exodus, maps, and paper engineering. The artworks were produce in the form of pop-up maps in A3 size when closed and A2 when opened, and 10 pop-ups / movables that explain the events in the story of the Exodus.
\end{abstract}

Keywords: exodus, pop-up map, engineering paper, Sunday school, Bible story

Correspondence author: Vanessa Yusuf, vanessa.yusuf.lim@gmail.com, Yogyakarta, Indonesia

\section{Pendahuluan}

Sekolah minggu merupakan kegiatan belajar mengajar mengenai Firman Tuhan yang dilakukan pada hari Minggu bagi anak-anak. Pengenalan tentang bermacam kisah Alkitab rutin 
diceritakan kepada anak-anak untuk dapat memahami makna cerita tersebut, mengenal teladan berbagai tokoh, dan terutama semakin mengenal Tuhan dan kehendak-Nya. Salah satu contoh kisah yang sering dibahas yaitu mengenai Eksodus. Eksodus merupakan kisah yang menceritakan tentang keluarnya Bangsa Israel dari Mesir menuju tanah Kanaan mulai dari kitab Keluaran ketika Musa lahir, hingga kitab Yosua ketika Bangsa Israel berhasil masuk ke tanah Kanaan (Beaumont). Perjalanan yang panjang ini melibatkan banyak tempat dan waktu yang berbedabeda.

Berdasarkan wawancara dengan guru-guru sekolah minggu di GRII, pada umumnya guru jarang menunjukkan tempat atau lokasi pada peta dari kisah yang diceritakan dan cenderung hanya menyebutkan nama tempatnya saja. Kemudian ketika ditanyakan, anak-anak sudah cukup familiar dengan nama-nama tempat seperti: Mesir, Gunung Sinai, Laut Teberau, Kanaan, Benteng Yerikho, Sungai Nil dan tempat-tempat lainnya. Namun tidak satu pun anak yang mengetahui posisi tempat tersebut, jaraknya, alur perjalanan, hingga lokasi di mana Bangsa Israel berputar-putar di padang gurun selama 40 tahun, sampai akhirnya tiba di tanah Kanaan. Pemahaman akan tempat dan alur perjalanan ini menjadi penting untuk dipelajari agar dapat memahami Firman Tuhan yang diceritakan secara total.

Menurut Kelvin (guru geografi di SKC, Jakarta) dalam wawancara yang dilakukan, peta dapat membantu orang untuk memvisualisasikan suatu kejadian dan semakin percaya bahwa kejadian tersebut adalah nyata. Maka dari itu penting adanya suatu peta untuk menceritakan kisah-kisah Alkitab khususnya yang melibatkan banyak tempat / lokasi seperti contohnya kisah Eksodus. Pada bagian belakang Alkitab umumnya terdapat beberapa lembar peta yang menunjukkan posisi dari berbagai tempat yang disebutkan dalam Alkitab. Namun peta hitamputih ini sering kali masih sulit dipahami baik oleh orang dewasa maupun anak-anak. Begitu pula pada kegiatan sekolah minggu perlu dirancang visualisasi peta yang sesuai untuk anak-anak, mudah dipahami, dan menarik untuk dipelajari.

Salah satu cara visualisasi yang digemari anak-anak yaitu dengan menggunakan mekanisme paper engineering atau lebih sering dikenal dengan sebutan pop-up. Paper engineering merupakan teknik memotong dan membuat bentuk pada kertas atau kartu untuk membuat pop-up, moving cards, dan mesin dengan hanya menggunakan kertas sebagai mekanismenya (Ives). Melalui mekanisme paper engineering ini suatu visual tidak hanya ditampilkan secara datar atau 2 dimensi, tetapi dapat pula ditampilkan dalam bentuk 3 dimensi. Paper engineering juga dapat menghasilkan pergerakkan pada ilustrasi untuk membuat gambar semakin nyata dan interaktif. Setiap pergerakkan yang diciptakan tidak hanya sekedar untuk menarik perhatian, tetapi juga mendukung makna yang ingin disampaikan dari gambar tersebut. Maka dari itu pada penelitian ini bertujuan untuk merancang sebuah peta pop-up tentang kisah Eksodus untuk membantu pemahaman anak melalui visual yang interaktif.

\section{Metode}

Perancangan peta pop-up Eksodus ini menggunakan metode kualitatif agar dapat mendesain media yang sesuai untuk menjelaskan kisah Eksodus kepada anak-anak. Pengumpulan data dilakukan melalui wawancara kepada guru sekolah minggu di GRII dan GPIB Surabaya, Pendeta di GPIB, dan guru geografi di SKC untuk mendapatkan informasi terkait materi kisah Eksodus yang perlu ditampilkan dalam peta pop-up, potensi peta pop-up sebagai alat peraga di dalam kelas sekolah minggu, hingga masukan-masukan untuk visualisasi perancangan ini. Kemudian observasi pada kelas sekolah minggu dilaksanakan untuk dapat mengetahui cara anak-anak belajar, memahami materi, dan kegunaan gambar maupun alat 
peraga dalam penyampaian kisah Alkitab. Studi perbandingan dengan karya sejenis juga dilakukan seperti pada atlas Alkitab dan buku cerita pop-up. Data-data tersebut dikaitkan dengan literatur terkait kisah Eksodus, paper engineering, dan peta, yang kemudian hasil analisanya digunakan dalam merancang peta pop-up Eksodus.

\section{Hasil dan Pembahasan}

Buku mengenai kisah Alkitab bagi anak-anak telah banyak dijumpai di toko-toko buku. Buku tersebut pada umumnya berupa buku datar yang dilengkapi cerita dan ilustrasi. Saat ini buku cerita pop-up tentang kisah Alkitab juga mulai bermunculan dan menarik minat anak-anak maupun orang tua. Berbeda dengan atlas Alkitab atau buku-buku yang berisi peta kejadiankejadian dalam kisah Alkitab, buku tersebut saat ini masih sedikit dijumpai terutama yang ditujukan bagi anak-anak. Pada tinjauan berikut ini membahas mengenai 2 buku peta dan 2 buku pop-up tentang kisah Alkitab yang diperuntukkan bagi anak-anak. Perancangan ini akan menggabungkan potensi-potensi dari buku-buku yang telah ada, untuk menciptakan suatu visualisasi peta yang mudah dimengerti dan menarik bagi anak-anak melalui mekanisme paper engineering / pop-up.

Tabel 1 Tinjauan Karya Serupa

\begin{tabular}{|c|c|c|}
\hline Gambar Buku & Keterangan Buku & Tinjauan Buku \\
\hline f lat & $\begin{array}{l}\text { Judul: Atlas Alkitab } \\
\text { Penerbit: Erlangga for Kids } \\
\text { Tahun Terbit: } 2007 \\
\text { Pengarang: June E. Darling }\end{array}$ & $\begin{array}{l}\text { Atlas Alkitab menjelaskan } 7 \\
\text { kisah Alkitab dengan masing- } \\
\text { masing kisah } 1 \text { spread halaman. } \\
\text { Setiap kisah diberikan nomor- } \\
\text { nomor kejadian penting pada } \\
\text { peta, kemudian dijelaskan dalam } \\
\text { paragraf singkat dan ilustrasi di } \\
\text { sekitar peta. }\end{array}$ \\
\hline & $\begin{array}{l}\text { Judul: Sunday School } \\
\text { Classroom Large Bible } \\
\text { Theme Wall Maps } \\
\text { Penerbit: Bible Society } \\
\text { Tahun Terbit: } 2010 \\
\text { Pengarang: Bible Society }\end{array}$ & $\begin{array}{l}\text { Pada ke-4 Peta ini membahas } 4 \\
\text { daerah dan topik besar dalam } \\
\text { Alkitab. Setiap topik tersebut } \\
\text { dijelaskan melalui peta } \\
\text { berwarna dengan keterangan } \\
\text { nama tempat dan sedikit } \\
\text { ilustrasi kecil. }\end{array}$ \\
\hline & $\begin{array}{l}\text { Judul: My Pop-up Bible } \\
\text { Stories } \\
\text { Penerbit: Candle Books } \\
\text { Tahun Terbit: } 2012 \\
\text { Pengarang: Juliet David }\end{array}$ & $\begin{array}{l}\text { Buku ini menampilkan beberapa } \\
\text { cerita Alkitab, salah satunya } \\
\text { tentang kelahiran Musa, yang } \\
\text { dijelaskan melalui paragraf } \\
\text { pendek serta ilustrasi pop-up 3D } \\
\text { untuk masing-masing cerita. }\end{array}$ \\
\hline
\end{tabular}




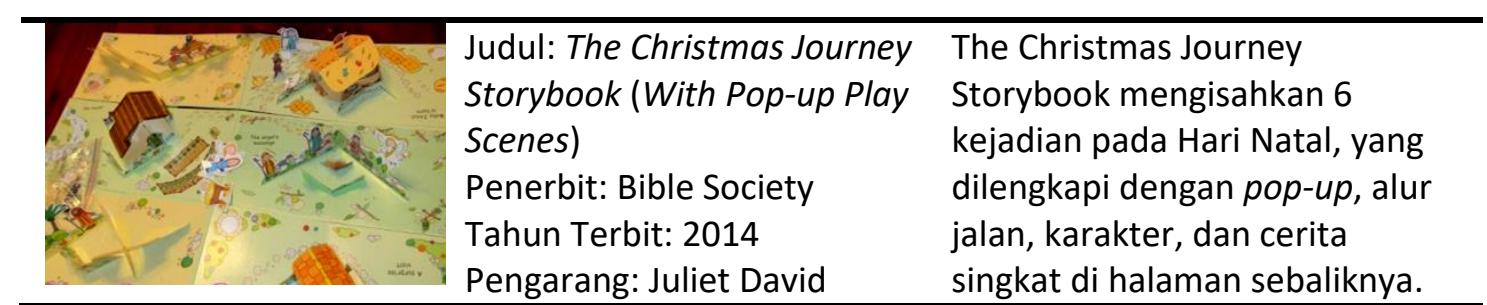

Dari hasil tinjauan keempat karya di atas terdapat poin-poin penting yang dapat dipelajari dan diterapkan pada perancangan ini yaitu:

1. Pemberian nomor pada setiap kejadian untuk membantu urutan peristiwa dalam peta.

2. Penggunaan ilustrasi untuk menjelaskan peritiwa yang terjadi pada setiap lokasi dalam peta.

3. Pemberian warna yang tepat dan menarik baik pada peta maupun ilustrasi.

4. Penulisan nama tempat yang menjadi titik terjadinya suatu peristiwa.

5. Pembuatan mekanisme pop-up yang pergerakannya disesuaikan dengan makna peristiwa.

6. Memberikan alur perjalanan untuk menuntun arah dari satu kejadian ke kejadian lain.

7. Menuliskan penjelasan singkat terkait peristiwa yang diilustrasikan pada peta.

\section{Kisah Eksodus}

Kisah mengenai Musa yang memimpin bangsa Israel untuk keluar dari Mesir menuju Tanah Perjanjian (Kanaan) telah menjadi kisah sering dibahas dalam materi sekolah minggu bagi anak-anak. Pada umumnya anak-anak telah hafal ke-10 tulah di Mesir, mengenal sosok Musa, mengetahui sikap dan kelakuan Bangsa Israel yang terus bersungut-sungut selama dipadang gurun. Anak-anak juga sering diceritakan mengenai berbagai mukjizat yang Tuhan berikan bagi bangsa Israel, seperti membelah Laut Teberau, menciptakan tiang api dan awan, memberikan manna dan puyuh, mengeluarkan air dari batu, hingga puncaknya memberikan tanah Kanaan kepada Bangsa Israel. Cerita ini juga memiliki latar tempat yang cukup banyak disebutkan dalam Alkitab, seperti: Rameses, Laut Terberau, Gunung Horeb, Gunung Sinai, Kadesh Barnea, Midian, Edom, Sungai Yordan, Kanaan, dan masih banyak lainnya. Namun apakah anak-anak tahu di mana letak tempat-tempat tersebut?

Menurut guru-guru sekolah minggu di GPIB dan GRII Surabaya, pembelajaran di kelas sangat jarang menjelaskan mengenai letak lokasi setiap tempat yang diceritakan kepada anak. Biasanya hanya nama tempat saja yang disebutkan dari tujuan awal hingga tujuan akhir. Penjelasan juga sering dibantu dengan ilustrasi di lembar aktivitas yang dibagikan kepada setiap anak seperti yang ditunjukkan pada Gambar 1. Contoh materi yang dibahas melalui aktivitas maupun alat peraga yaitu seperti: tokoh-tokoh, benda-benda yang berhubungan, dan alur perkembangan dulu hingga saat ini, serta makna dari kisah tersebut. Berdasarkan hasil dari wawancara, guru-guru sekolah minggu maupun guru geografi sebenarnya berpendapat bahwa penting adanya penunjukkan lokasi kejadian beserta alurnya, karena anak dapat lebih memahami kisah yang diceritakan, lebih mudah membayangkan, semakin mempercayai kisah tersebut, bahkan mendapat pemahaman yang lebih komprehensif terkait rencana besar Tuhan bagi manusia di tempat tertentu sesuai kisah yang sedang dibahas. 


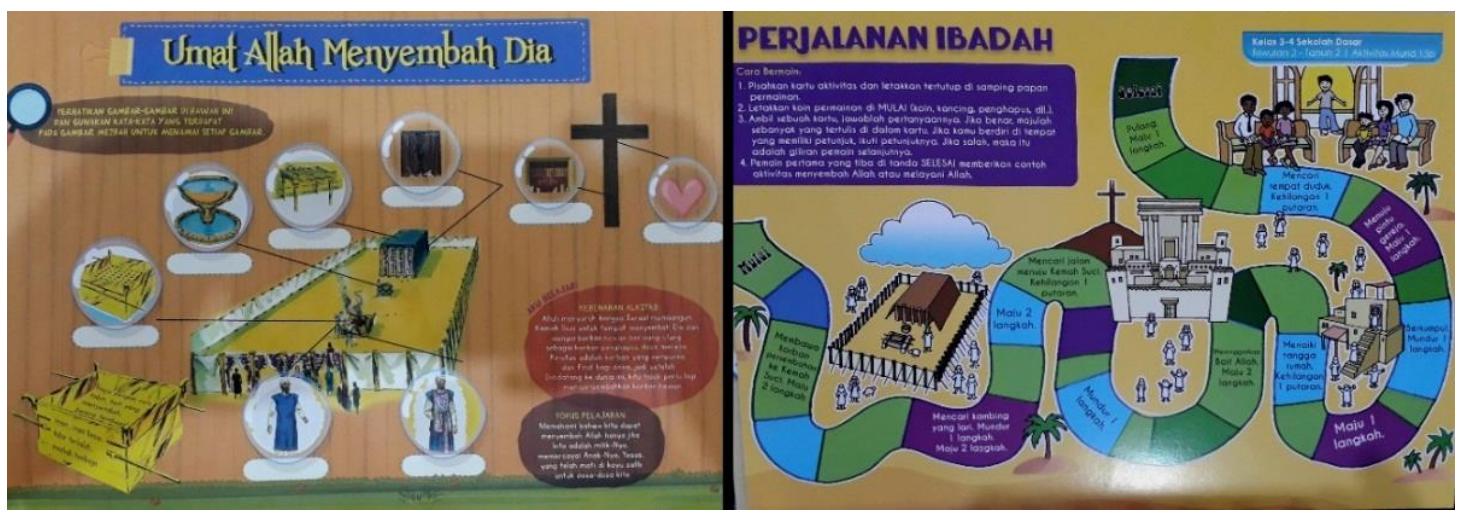

Gambar 1 Lembar Aktivitas Sekolah Minggu di GRII

Sumber: Dokumentasi Pribadi

Peta kisah Alkitab sendiri ada berbagai macam, contoh yang paling mudah ditemui adalah peta yang berada di belakang Alkitab. Namun tampilan peta tersebut belum terlalu detil dan ketika ditanyakan, bagi orang dewasa dan anak-anak sering kali masih sulit dalam membaca peta di Alkitab ini. Seperti saat wawancara sempat diceritakan pengalaman lampau ketika melihat peta di Alkitab, ternyata mengalami kesulitan untuk membedakan mana daratan dan mana lautan karena peta tidak berwarna dan hanya berupa garis-garis saja. Maka dari itu untuk membuat suatu peta harus dapat mudah dimengerti oleh pelihatnya agar tidak salah mengerti informasi.

\section{Peta Eksodus}

Peta yang baik harus dapat menjelaskan suatu lokasi dan mudah dimengerti oleh pelihatnya. Pada atlas-atlas yang ada saat ini dapat diamati ada berbagai elemen utama dalam peta yang yang harus ditampilkan. Komponen-komponen pada peta terdiri dari (Fatma):

1. Judul: Kata/kalimat yang menerangkan gambar peta yang dimaksud secara ringkas dan jelas.

2. Skala: Perbandingan antara jarak yang ada di peta dengan jarak pada lokasi aslinya dengan menggunakan garis/batang sebagai pembanding.

3. Orientasi Peta: Arah mata angin untuk menunjukkan arah utara, selatan, timur, dan barat. Pada umumnya bagian atas peta merupakan arah utara.

4. Inset: Gambaran lokasi yang lebih menyeluruh dan lebih mudah dikenali untuk menunjukkan posisi lokasi gambaran peta yang kurang dikenali.

5. Sumber dan Pembuat Peta: Lembaga yang melakukan riset dan membuat peta tersebut.

6. Tahun Pembuatan: Tahun peta dibuat oleh lembaga dari hasil riset yang telah dilakukan.

7. Simbol: Tanda berupa gambar sederhana yang mewakili suatu objek seperti: gunung, ibu kota, jalur, dan lainnya.

8. Legenda: Penjelasan mengenai makna berbagai simbol yang ditampilkan pada peta.

9. Garis Astronomis: Garis lintang maupun garis bujur pada peta yang digunakan untuk penentuan seperti waktu dan musim pada suatu daerah.

10. Tata Penulisan: Tata cara menulis nama tempat seperti ibu kota, samudera, gunung, sungai, danau, dan lainnya menggunakan huruf besar, huruf kecil, maupun huruf miring.

11. Warna: Pemberian warna pada peta dapat menunjukkan arti teretentu, seperti hijau untuk daratan, biru untuk laut, sungai, samudera, dan warna-warna lainnya.

Elemen-elemen pada peta tersebut menjadi salah satu kriteria utama dalam visualisasi peta pop-up yang dirancang pada penelitian ini. Tidak hanya memenuhi persyaratan elemen peta saja, tetapi peta yang dikhususkan untuk anak-anak juga memerlukan visualisasi yang 
mudah dipahami dan menarik untuk dipelajari. Salah satu cara visualisasi yang dapat dilakukan yaitu dengan menambahkan ilustrasi, teks, dan juga mekanisme pop-up, seperti pada observasi yang dilaksanakan di GPIB Surabaya. Berdasarkan pengalaman dalam mengajar, guru-guru sekolah minggu yang diwawancarai berpendapat bahwa interaksi pada alat peraga dapat membuat anak-anak lebih tertarik dan semakin terbayang peristiwa yang sedang diceritakan. Kemudian untuk tulisan pada gambar juga disarankan menggunakan ukuran yang lebih besar agar mudah terbaca oleh anak-anak.

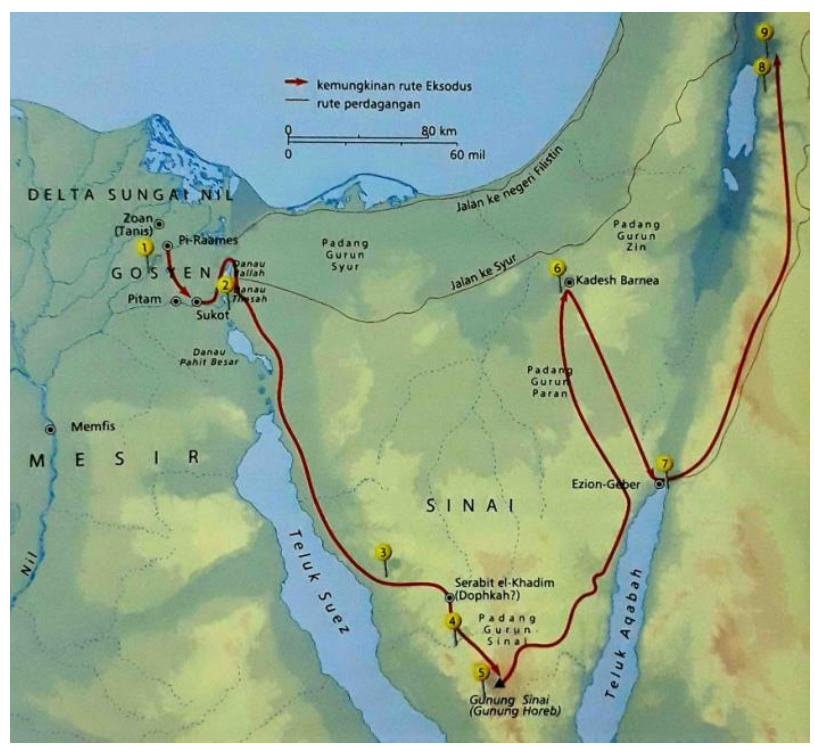

Gambar 2 Peta Eksodus

Sumber: Ensiklopedia Alkitab Tematik (Beaumont)

Peta pop-up yang dirancang pada penelitian ini tidak hanya menjelaskan tempat, tetapi juga menceritakan kejadian-kejadian penting yang terjadi saat bangsa Israel menuju tanah Kanaan. Rangkaian peristiwa keluarnya bangsa Israel dari Mesir menuju Kanaan ini terdapat 10 kejadian yang akan ditunjukkan dalam peta pop-up. Pemilihan kesepuluh kejadian tersebut ditentukan setelah berkonsultasi dengan Pendeta Deviyanti untuk dapat mewakili kejadiankejadian penting dari awal hingga akhir kisah Eksodus. Berikut ini ke-10 peristiwa yang dipilih:

1. Kelahiran Musa dan diangkatnya Musa oleh putri Firaun di Sungai Nil

2. Musa mendapat tanda dari Tuhan berupa semak duri berapi di Gunung Horeb

3. Kesepuluh tulah di Mesir

4. Terbelahnya laut Teberau

5. Turunnya manna dan burung puyuh bagi Israel di Padang Gurun Sin

6. Musa mendapat 2 loh batu berisi 10 Perintah Allah dan peristiwa penyembahan bangsa Israel pada lembu emas di Gunung Sinai.

7. Pembangunan Tabernakel dan Tabut Perjanjian

8. Pengintaian 10 orang ke tanah perjanjian dari Kadesh Barnea

9. Peristiwa patung ular tembaga di Edom

10. Robohnya Benteng Yerikho dan Bangsa Israel berhasil masuk ke tanah Kanaan

\section{Mekanisme Paper Engineering dan Konsep Perancangan Peta Pop-up Eksodus}

Setelah menentukan kesepuluh kejadian tersebut, memerlukan bentuk pop-up atau paper engineering yang sesuai. Paper engineering sendiri memiliki beragam mekanisme, dan pada visualisasi peta ini hal yang menjadi perhatian utama adalah bentuk peta dari Mesir hingga 
Kanaan, serta perlunya menonjolkan 10 peristiwa yang akan ditampilkan. Peta menampilkan gambar secara datar, sedangkan paper engineering atau pop-up dapat menciptakan bentuk 3D dan juga ketinggian atau volume pada suatu gambar. Melalui pop-up dapat menjadi cara yang menakjubkan untuk membawa berbagai konsep ke dalam kehidupan dengan cara yang sangat nyata dan mudah dipahami bagi segala umur, bahkan menjadi media yang sempurna untuk memvisualisasikan ilustrasi non-fiksi (McCannon et al.)

Secara umum mekanisme paper engineering dapat dibagi menjadi 3 macam yaitu: movables, pop-up, dan folding mechanism (Van Dyk et al.). Ketiga jenis mekanisme tersebut memiliki bentuk dan cara penggunaan yang berbeda. Pemilihan penggunaan mekanisme ini disesuaikan dengan cerita yang diangkat dan target audience atau penggunanya. Pada alat peraga yang dirancang, untuk dapat membuat peta menjadi fokus utama maka posisi peta perlu lebih menonjol dibandingkan keterangan lainnya. Mekanisme yang sesuai untuk menaikkan posisi peta ini yaitu dengan menggunakan mekanisme pop-up parallel fold. Sehingga letak peta sudah setingkat lebih tinggi dibandingkan dasar kertas atau halamannya seperti yang ditampilkan pada Gambar 3. Kemudian untuk menandai kesepuluh kejadian yang dipilih, maka posisi kejadian tersebut harus dibuat berdiri pada peta tersebut.

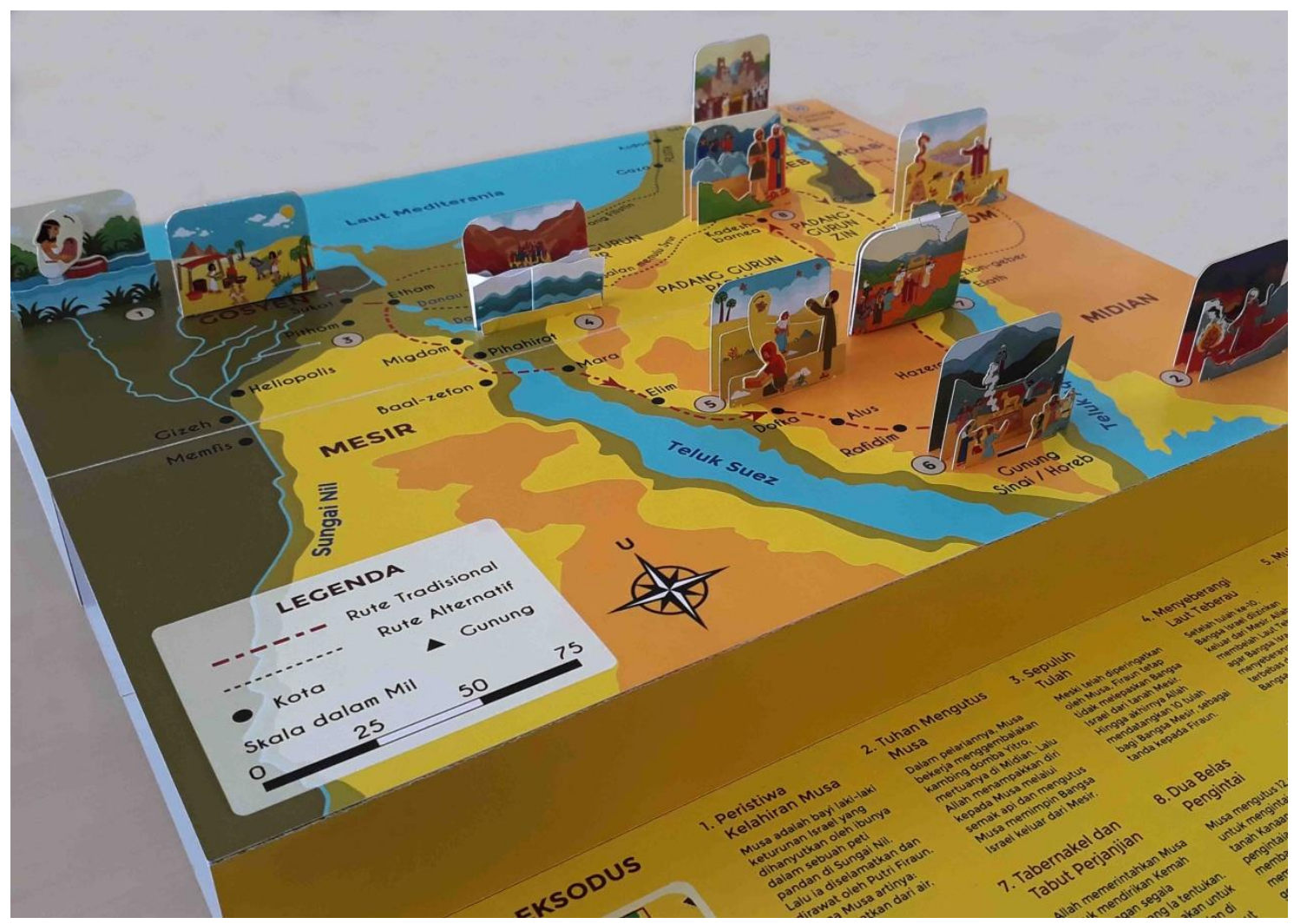

Gambar 3 Desain Peta Pop-up Eksodus

Sumber: Dokumentasi Pribadi

Fungsi pop-up atau paper engineering tidak hanya untuk menciptakan bentuk 3D tetapi juga untuk membuat pergerakkan pada gambar (movables). Pop-up dapat digunakan sebagai dasar untuk permukaan grafis, mentransformasi hasil cetak 2D yang konvensional menjadi objek 3D yang menarik perhatian, dapat dipegang, dimainkan, dipajang, dan dikagumi (Jackson). Seperti pada kesepuluh kejadian yang dibahas ini perlu mekanisme kertas yang sesuai dengan makna kejadian tersebut. Setiap gerakan mekanisme kertas yang dirancang harus selaras dan 
logis dengan gerakan dan maksud dari peristiwa yang ditampilkan. Berikut ini hasil analisa pemilihan mekanisme paper engineering beserta hasil desain yang sesuai untuk kesepuluh kejadian terpilih.

Tabel 2 Visualisasi dan Mekanisme Peta Pop-up Eksodus

\begin{tabular}{cll}
\hline No & Peristiwa Eksodus & Mekanisme \& Maknanya \\
\hline 1 & $\begin{array}{l}\text { Kelahiran Musa dan } \\
\text { diangkatnya Musa } \\
\text { oleh putri Firaun di } \\
\text { sungai Nil }\end{array}$ & $\begin{array}{l}\text { Mekanisme movables: wheel } \\
\text { Gerakan memutar menunjukkan } \\
\text { ketika Musa diangkat dari air } \\
\text { oleh Putri Firaun, sesuai dengan } \\
\text { arti nama Musa. }\end{array}$ \\
\hline 2 & $\begin{array}{l}\text { Musa mendapat } \\
\text { tanda dari Tuhan } \\
\text { berupa semak duri } \\
\text { berapi di Gunung } \\
\text { Horeb }\end{array}$ & $\begin{array}{l}\text { Mekanisme movables: pull-tab } \\
\text { Melalui gerakan tarik dan juga } \\
\text { terkesan berjalan mendekati } \\
\text { semak duri. }\end{array}$ \\
&
\end{tabular}

3 Kesepuluh tulah di Mekanisme pop-up angle fold Mesir

Pada bagian awal gambar menunjukan kondisi Mesir sebelum terkena tulah. Ketika pop-up dibuka, tampak ilustrasi ke-10 tulah secara 3 dimensi.

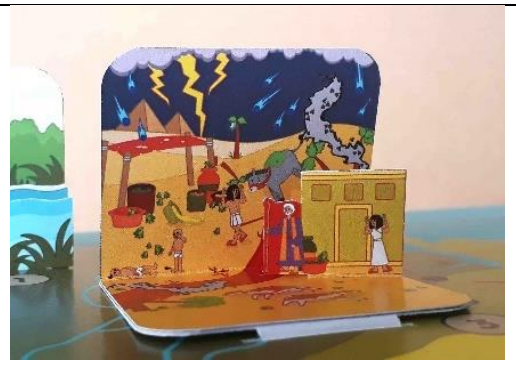

\begin{tabular}{|c|c|c|}
\hline 4 & $\begin{array}{l}\text { Terbelahnya laut } \\
\text { Teberau }\end{array}$ & $\begin{array}{l}\text { Mekanisme movables: pull-tab } \\
\text { Gerakan mekanisme menggeser } \\
\text { air ke kanan dan ke kiri untuk } \\
\text { menampilkan proses } \\
\text { terbelahnya Laut Teberau } \\
\text { menjadi } 2 \text { dinding air yang } \\
\text { tinggi. }\end{array}$ \\
\hline 5 & $\begin{array}{l}\text { Turunnya manna } \\
\text { dan burung puyuh } \\
\text { bagi Bangsa Israel di } \\
\text { Padang Gurun Sin }\end{array}$ & $\begin{array}{l}\text { Mekanisme movables: wheel } \\
\text { Mekanisme dapat digerakkan } \\
\text { pada satu pusat poros untuk } \\
\text { membuat burung puyuh tampak } \\
\text { turun dari langit kemudian } \\
\text { ditangkap dan juga gerakan }\end{array}$ \\
\hline
\end{tabular}


orang mengambil manna yang

bertebaran di tanah.

$\begin{array}{ll}6 & \text { Musa mendapat } 2 \\ & \text { loh batu berisi } 10 \\ & \text { Perintah Allah dan } \\ & \text { peristiwa } \\ \text { penyembahan } & \\ \text { Bangsa Israel pada } \\ \text { patung lembu emas } \\ \text { di Gunung Sinai. }\end{array}$

Mekanisme pop-up layer

Pop-up layer menampilkan gambar Musa yang turun dari Gunung Sinai dengan membawa 2 loh batu pada layer belakang. Layer depan menunjukkan situasi ketika Bangsa Israel sedang menyembah patung lembu emas.

\begin{tabular}{lll}
\hline 7 & Pembangunan & Mekanisme pop-up: parallel fold \\
Tabernakel dan & \\
Tabut Perjanjian & Pada saat pop-up tertutup, \\
& tampak ilustrasi para Imam yang \\
& membawa tabut perjanjian. \\
& Kemudian ketika pop-up dibuka \\
& tampak tabernakel (kemah suci) \\
& yang letaknya persis di bawah \\
& tiang awan atau tiang api.
\end{tabular}

\begin{tabular}{|c|c|c|}
\hline 8 & $\begin{array}{l}\text { Pengintaian } 10 \\
\text { orang ke tanah } \\
\text { perjanjian dari } \\
\text { Kadesh barnea }\end{array}$ & $\begin{array}{l}\text { Mekanisme movables: pull-tab } \\
\text { Tampilan awal tampak para } \\
\text { pengintai sedang melihat orang- } \\
\text { orang Kanaan. Ketika ditarik } \\
\text { tampak } 2 \text { pengintai pergi } \\
\text { membawa buah yang besar hasil } \\
\text { pengintaian. }\end{array}$ \\
\hline 9 & $\begin{array}{l}\text { Peristiwa patung } \\
\text { ular tembaga di } \\
\text { Edom }\end{array}$ & $\begin{array}{l}\text { Mekanisme movables: pull-tab } \\
\text { Ketika mekanisme ditarik dan } \\
\text { dorong, maka akan tampil } \\
\text { gerakan orang yang mendekati } \\
\text { dan melihat patung ular } \\
\text { tembaga agar sakitnya pulih dan } \\
\text { tidak menjadi mati akibat dari } \\
\text { gigitan ular. }\end{array}$ \\
\hline 10 & $\begin{array}{l}\text { Runtuhnya Tembok } \\
\text { Yerikho dan Bangsa } \\
\text { Israel berhasil } \\
\text { masuk tanah } \\
\text { Kanaan. }\end{array}$ & $\begin{array}{l}\text { Mekanisme pop-up: pivot wheel } \\
\text { Pop-up terdiri dari } 2 \text { sisi gambar. } \\
\text { Sisi pertama menunjukkan } \\
\text { ketika Bangsa Israel mulai } \\
\text { memutari tembok Yerikho. Sisi } \\
\text { sebaliknya ketika diputar akan } \\
\text { menunjukkan gambar Tembok } \\
\text { Yerikho yang runtuh. }\end{array}$ \\
\hline
\end{tabular}

Peta pop-up ini dirancang berukuran A3 dengan tinggi $1 \mathrm{~cm}$ saat tertutup dan saat dibuka menjadi ukuran A2 dengan tinggi $10 \mathrm{~cm}$. Ukuran peta dibuat cukup besar dengan 
mempertimbangkan proses belajar-mengajar yang dilaksanakan dalam sekolah minggu, agar memudahkan guru ketika menjelaskan, dan anak-anak juga dapat berinteraksi langsung dengan pop-up yang ditampilkan. llustrasi yang digunakan yaitu flat design untuk dapat menampilkan gambar yang menarik bagi anak-anak, tidak rumit, dan merupakan bentuk penyederhaan visual tanpa memberikan penambahan pada proporsi objek tertentu. Karya ini menggunakan warnawarna cerah yang digemari anak serta disesuaikan dengan setiap peristiwa yang digambarkan. Outline juga digunakan untuk mempertegas gambar baik objek benda, orang, tanaman, hewan, maupun latar tempat. Pada setiap peristiwa diberikan nomor di sampingnya untuk memudahkan ketika melihat urutan kejadian.

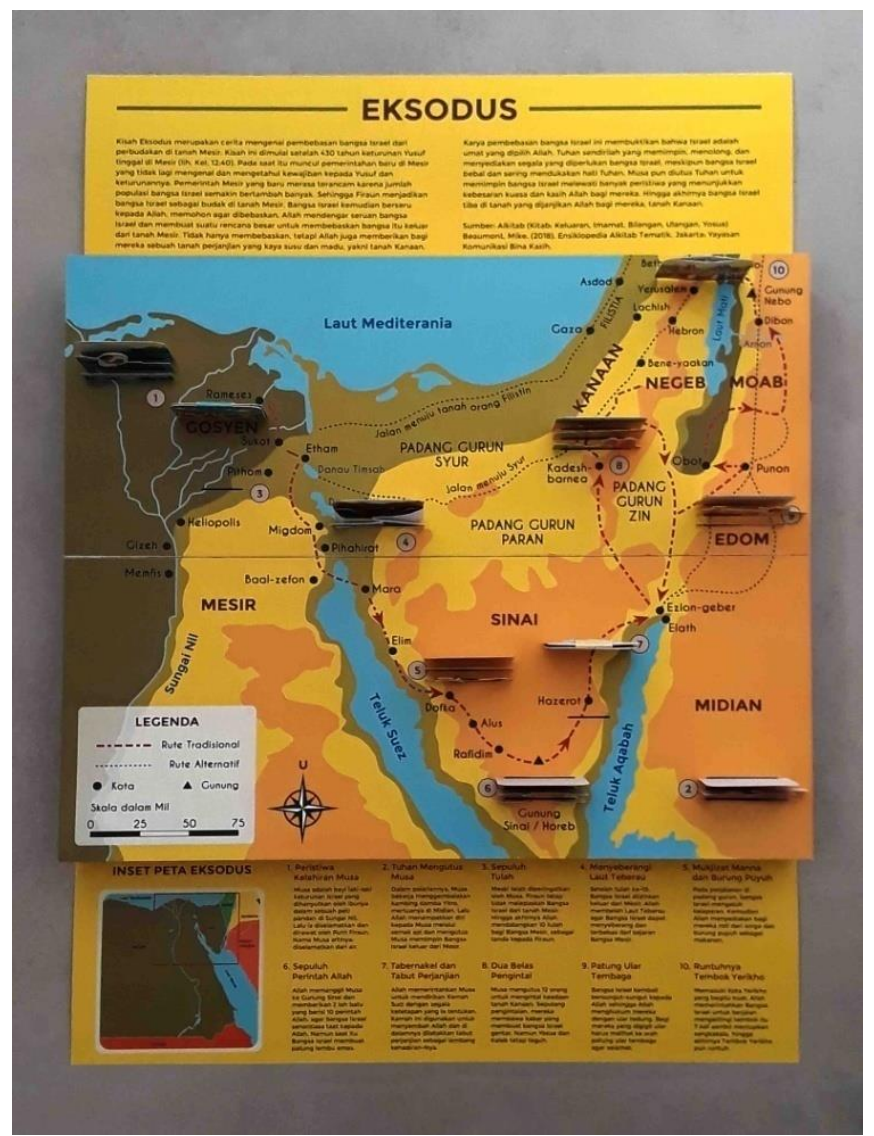

Gambar 4 Peta Pop-up Eksodus

Sumber: Dokumentasi Pribadi

Kemudian sesuai dengan pembahasan mengenai elemen-elemen peta sebelumnya, pada perancancangan ini menerapkan setiap elemen-elemen tersebut. Pada peta, warna yang digunakan disesuaikan dengan tinggi dataran tersebut. Berbagai simbol-simbol yang ada di peta juga diberikan keterangan pada bagian kiri bawah, sebagai contoh simbol bulat hitam berarti kota dan simbol segitiga hitam berarti gunung. Terdapat pula skala batang untuk memudahkan guru sekolah Minggu ketika menjelaskan seberapa besar ukuran asli dari peta ini. Di bagian bawah terdapat Inset untuk menunjukkan lokasi kejadian Eksodus pada peta yang lebih meluas (zoom out) agar dapat mudah dikenali posisinya di dunia ini. Ada pula perbedaan warna alur perjalanan yaitu warna merah untuk rute tradisional dan warna hijau untuk rute alternatif. Penampilan ragam rute tersebut dapat dijelaskan oleh guru kepada anak-anak tentang mengapa rute yang lebih panjang dan memutar yang harus dilalui oleh Bangsa Israel dibandingkan dengan rute alternatif yang tampak jauh lebih sederhana dan pendek. Hal ini akan menjadi penjelasan 
yang sangat baik dan mudah dimengerti tentang alasan pemilihan alur perjalanan Bangsa Israel yang ditetapkan Allah sesuai yang diterangkan dalam kitab Keluaran 13:17-18. Kemudian di samping inset juga diberikan penjelasan singkat mengenai kesepuluh peristiwa yang ditampilkan pada peta pop-up. Berikut ini penjelasan ke-10 kejadian:

1. Peristiwa Kelahiran Musa

Musa adalah bayi laki-laki keturunan Israel yang dihanyutkan oleh ibunya dalam sebuah peti pandan di Sungai Nil. Lalu ia diselamatkan dan dirawat oleh Putri Firaun. Nama Musa artinya: diselamatkan dari air.

2. Tuhan Mengutus Musa

Dalam pelariannya, Musa bekerja menggembalakan kambing domba Yitro, mertuanya di Midian. Lalu Allah menampakkan diri kepada Musa melalui semak api dan mengutus Musa memimpin Bangsa Israel keluar dari Mesir.

3. Sepuluh Tulah

Meski telah diperingatkan oleh Musa, Firaun tetap tidak melepaskan Bangsa Israel dari tanah Mesir. Hingga akhirnya Allah mendatangkan 10 tulah bagi Bangsa Mesir, sebagai tanda kepada Firaun.

4. Menyeberangi Laut Teberau

Setelah tulah ke-10, Bangsa Israel diizinkan keluar dari Mesir. Allah membelah Laut Teberau agar Bangsa Israel dapat menyeberang dan terbebas dari kejaran Bangsa Mesir.

5. Mukjizat Manna dan Burung Puyuh

Pada perjalanan di padang gurun, Bangsa Israel mengeluh kelaparan. Kemudian Allah menyediakan bagi mereka roti dari sorga dan burung puyuh sebagai makanan.

6. Sepuluh Perintah Allah

Allah memanggil Musa ke Gunung Sinai dan memberikan 2 loh batu yang berisi 10 perintah Allah, agar bangsa Israel senantiasa taat kepada Allah. Namun saat itu Bangsa Israel membuat patung lembu emas.

7. Tabernakel dan Tabut Perjanjian

Allah memerintahkan Musa untuk mendirikan Kemah Suci dengan segala ketetapan yang la tentukan. Kemah ini digunakan untuk menyembah Allah dan di dalamnya diletakkan tabut perjanjian sebagai lambang kehadiran-Nya.

8. Dua Belas Pengintai

Musa mengutus 12 orang untuk mengintai keadaan tanah Kanaan. Sepulang pengintaian, mereka membawa kabar yang membuat Bangsa Israel gentar. Namun Yosua dan Kaleb tetap teguh.

9. Patung Ular Tembaga

Bangsa Israel kembali bersungut-sungut kepada Allah sehingga Allah menghukum mereka dengan ular tedung. Bagi mereka yang digigit ular harus melihat ke arah patung ular tembaga agar selamat. 
10. Runtuhnya Tembok Yerikho

Memasuki Kota Yerikho yang begitu kuat, Allah memerintahkan Bangsa Israel untuk berjalan mengelilingi tembok itu 7 kali sambil meniupkan sangkakala, hingga akhirnya Tembok Yerikho pun runtuh.

\section{Simpulan}

Kisah Alkitab rutin diceritakan kepada anak-anak pada saat Sekolah Minggu. Pada setiap kisah tersebut terdapat banyak tempat yang berkaitan dengan alur peristiwa yang berlangsung. Salah satu contoh kisah yang melibatkan banyak tempat yaitu kisah Eksodus (peristiwa keluarnya Bangsa Israel dari Mesir menuju Kanaan). Hingga saat ini penggunaan peta masih sangat jarang dalam pembelajaran kelas sekolah minggu. Peta kisah Alkitab yang ditujukan khusus bagi anak-anak juga masih jarang ditemukan di pasaran. Maka dari itu pada penelitian ini merancang sebuah peta kisah Alkitab (studi kasus: kisah Eksodus) dengan menggunakan pendekatan teknik pop-up / paper engineering yang sesuai untuk anak-anak.

Berdasarkan hasil analisa dari beragam sumber data, maka diambil sepuluh peristiwa penting dalam kisah Eksodus untuk ditampilkan dalam peta pop-up. Peta berukuran A2 ini dirancang dengan membuat gambar peta tampak timbul dengan dilengkapi alur perjalanan dan ilustrasi pop-up untuk kesepuluh peristiwa tersebut. Masing-masing mekanisme paper engineering pada kesepuluh ilustrasi ini dirancang dengan mempertimbangkan kaitan antara gerakan dan bentuk yang dihasilkan dengan makna dari peristiwa yang ingin ditampilkan. Sehingga peta pop-up ini dapat menjadi alat peraga yang tepat untuk membantu guru sekolah Minggu ketika menjelaskan kisah Eksodus kepada anak-anak.

\section{Daftar Pustaka}

Beaumont, Mike. Ensiklopedi Alkitab Tematik. Yayasan Komunikasi Bina Kasih, 2018.

Fatma, Desy. "Komponen Peta: Judul, Skala, Mata Angin, Dsb." IImuGeografi.com 23 Mei 2017 https://ilmugeografi.com/kartografi/komponen-peta. Accessed 2 September 2019.

Ives, Rob. Paper Engineering and Pop-Ups for Dummies. John Wiley \& Sons, 2009.

Jackson, Paul. Cut and Fold Techniques for Pop-up Designs. Laurence King Publishing, 2014.

McCannon, Desdemona et al. The Encyclopedia of Writing and Illustrating Children's Books: From Creating Characters to Developing Stories, a Step-by-Step Guide to Making Magical Picture Books. Running Press, 2008.

Van Dyk, Stephen et al. Paper Engineering: Fold, Pull, Pop \& Turn. Smithsonian Institution, 2010. 